\title{
Serum magnesium levels and risk of coronary artery disease: Mendelian randomisation study
}

\author{
Susanna C. Larsson ${ }^{1 *}$, Stephen Burgess ${ }^{2,3}$ and Karl Michaëlsson ${ }^{4}$
}

\begin{abstract}
Background: Observational studies have shown that serum magnesium levels are inversely associated with risk of cardiovascular disease, but whether this association is causal is unknown. We conducted a Mendelian randomisation study to investigate whether serum magnesium levels may be causally associated with coronary artery disease (CAD).

Methods: This Mendelian randomisation analysis is based on summary-level data from the CARDloGRAMplusC4D consortium's 1000 Genomes-based genome-wide association meta-analysis of 48 studies with a total of 60,801 CAD cases and 123,504 non-cases. Six single-nucleotide polymorphisms associated with serum magnesium levels at genome-wide significance were used as instrumental variables.

Results: A genetic predisposition to higher serum magnesium levels was inversely associated with CAD. In conventional Mendelian randomisation analysis, the odds ratio of CAD was 0.88 ( $95 \%$ confidence interval $[C I] 0.78$ to $0.99 ; P=0.03$ ) per $0.1-\mathrm{mmol} / \mathrm{L}$ (about 1 standard deviation) increase in genetically predicted serum magnesium levels. Results were consistent in sensitivity analyses using the weighted median and heterogeneity-penalised model averaging methods, with odds ratios of $0.84(95 \% \mathrm{Cl} 0.72$ to $0.98 ; P=0.03)$ and $0.83(95 \% \mathrm{Cl} 0.71$ to $0.96 ; P=0.02)$, respectively.

Conclusions: This study based on genetics provides evidence that serum magnesium levels are inversely associated with risk of CAD. Randomised controlled trials elucidating whether magnesium supplementation lowers the risk of CAD, preferably in a setting at higher risk of hypomagnesaemia, are warranted.
\end{abstract}

Keywords: Coronary artery disease, Magnesium, Mendelian randomisation, Single-nucleotide polymorphisms

\section{Background}

Magnesium is the second most abundant intracellular cation. It plays a crucial role in many processes regulating cardiovascular function, such as vascular tone, endothelial function and myocardial excitability, and it is involved in regulation of glucose and insulin metabolism $[1,2]$. Experimental evidence indicates that magnesium insufficiency promotes atherosclerosis and that magnesium fortification attenuates atherogenesis [2-7]. Moreover, randomised controlled trials have shown that magnesium supplementation improves endothelial function $[8,9]$ and reduces blood pressure [8, 10-12], arterial stiffness [13], fasting glucose [12, 14], insulin resistance [15] and

\footnotetext{
* Correspondence: susanna.larsson@ki.se

${ }^{1}$ Unit of Nutritional Epidemiology, Institute of Environmental Medicine,

Karolinska Institutet, 17177 Stockholm, Sweden

Full list of author information is available at the end of the article
}

postoperative arrhythmias [16, 17]. Randomised controlled trials assessing whether magnesium supplementation may prevent cardiovascular events are lacking.

Evidence from observational studies indicates that high circulating magnesium levels and magnesium intake are associated with a modest reduction in risk of cardiovascular disease, including coronary heart disease $[18,19]$, but the causality of these associations is unknown. The observed inverse association between magnesium and cardiovascular disease may be due to confounding by other potentially cardioprotective nutrients in magnesium-rich foods or by health behaviours adopted by individuals consuming these foods. Rich food sources of magnesium include green leafy vegetables, legumes, nuts, seeds, avocados, dark chocolate, whole grains, yoghurt and fish. It has been estimated that magnesium intake from a normal Western diet is often inadequate. In the USA, two-thirds

(c) The Author(s). 2018 Open Access This article is distributed under the terms of the Creative Commons Attribution 4.0 International License (http://creativecommons.org/licenses/by/4.0/), which permits unrestricted use, distribution, and reproduction in any medium, provided you give appropriate credit to the original author(s) and the source, provide a link to the Creative Commons license, and indicate if changes were made. The Creative Commons Public Domain Dedication waiver (http://creativecommons.org/publicdomain/zero/1.0/) applies to the data made available in this article, unless otherwise stated. 
of the adult population has a magnesium intake below the estimated average requirement [20].

Exploiting genetic variants as instrumental variables of an exposure can strengthen causal inference regarding an exposure-outcome relationship. This technique, known as Mendelian randomisation (MR), reduces confounding because genetic variants are randomly allocated at meiosis and thus should be unrelated to self-selected lifestyle factors and behaviours. It also overcomes reverse causation bias since allelic randomisation always precedes the onset of disease. Causal inference from an MR study relies on the instrumental variable assumptions, which require that the genetic variant is robustly associated with the exposure; independent of confounders of the exposure-outcome relationship; and influences the outcome through the exposure only and not through any alternative causal pathway (Fig. 1) [21].

We applied a two-sample MR framework to determine the causal association between serum magnesium levels and coronary artery disease (CAD).

\section{Methods}

\section{Genetic variants and data sources}

We used an MR study design based on publicly available summary-level data from genome-wide association studies (GWASs) (Table 1). As instrumental variables for the MR analyses, we selected all single-nucleotide polymorphisms (SNPs) associated with serum magnesium levels at genome-wide significance $\left(P<5 \times 10^{-8}\right)$ in the largest available GWAS on serum magnesium levels [22]. We selected all six SNPs that achieved genomewide significance in the joint analysis of the discovery ( $n=15,366$ individuals) and replication $(n=8463$ individuals) cohorts [22]. All the SNPs were in different genomic regions and in linkage equilibrium.

Summary-level data (beta coefficients and standard errors) for the associations of the six magnesium-associated

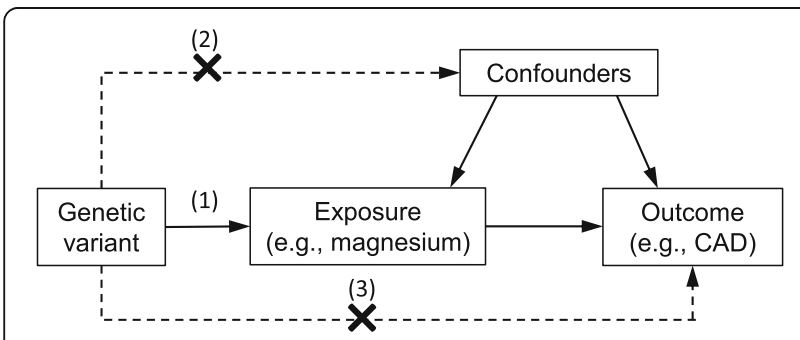

Fig. 1 Diagram of the instrumental variables assumptions for Mendelian randomisation. The three assumptions are: (1) the genetic variant must be robustly associated with the exposure; (2) the genetic variant should not be associated with confounders of the exposure-outcome association; and (3) the genetic variant must influence the outcome through the exposure only and not through any direct or alternative pathways. The dashed lines represent pathways that violate the assumptions. CAD coronary artery disease
SNPs with CAD were acquired from the CARDIoGRAMplusC4D consortium's 1000 Genomes-based genome-wide association meta-analysis of 60,801 CAD cases and 123,504 non-cases from 48 studies [23]. One SNP (rs7965584) was not part of the CARDIoGRAMplusC4D dataset and was replaced by a linked SNP (rs10858938; $r^{2}=0.96$ in Europeans). In the CARDIoGRAMplusC4D consortium, $\mathrm{CAD}$ was defined using a broad definition that included myocardial infarction (about 70\% of the total number of cases), acute coronary syndrome, chronic stable angina or coronary artery stenosis of at least 50\% [23]. Ethical approval was not sought, because this study involved analysis of publicly available summary-level data (beta coefficients and standard errors) from GWASs, and no individual-level data were used.

\section{Statistical analysis}

The main analysis was conducted using the conventional inverse-variance weighted method [24] (hereafter referred to as conventional MR analysis). Several sensitivity analyses were carried out, including (1) the leave-one-out analysis, in which one SNP in turn was removed to evaluate the impact of outlying SNPs; (2) the weighted median method, which gives accurate estimates if at least $50 \%$ of the instrumental variables are valid [24]; (3) the heterogeneity-penalised model averaging method, which provides consistent estimates if a plurality of the instrumental variables are valid [25]; and (4) MR-Egger regression, which can detect and adjust for pleiotropy [24, 26]. MR-Egger is disposed to effect estimate dilution due to the NO Measurement Error (NOME) assumption for the instrument-exposure associations. The NOME assumption was tested using the $I^{2}$ GX statistic, and the MR-Egger estimate was adjusted for dilution using the simulation extrapolation (SIMEX) method [27]. The strength of the instrumental variables was assessed using the F-statistic [28].

To investigate potential pleiotropy and mediating pathways from serum magnesium to CAD, we performed conventional $M R$ analyses of the association of serum magnesium levels with cardiometabolic risk factors, using publicly available GWAS data [29-34] (Table 1).

All reported odds ratios (ORs) with their 95\% confidence intervals (CIs) are scaled to a $0.1-\mathrm{mmol} / \mathrm{L}$ (about one standard deviation [SD]) increase in serum magnesium levels. All statistical tests were two-sided and considered statistically significant at $P<0.05$. The analyses were conducted using the mrrobust [35] and MendelianRandomization [36] packages.

\section{Results}

The six magnesium-associated SNPs explained $1.62 \%$ of the variance in serum magnesium levels, and the mean $F$-statistic was 64 (Table 2). Five of the SNPs were 
Table 1 Details of studies and datasets used for analyses

\begin{tabular}{|c|c|c|c|}
\hline Exposure/outcome & Consortium & Participants & Web source if publicly available \\
\hline Serum magnesium & CHARGE and replication studies [22] & $\begin{array}{l}23,829 \text { individuals of European } \\
\text { ancestry }\end{array}$ & Not available \\
\hline Coronary artery disease & $\begin{array}{l}\text { CARDloGRAMplusC4D consortium's } \\
1000 \text { Genomes-based GWAS [23] }\end{array}$ & $\begin{array}{l}184,305 \text { individuals (60,801 CAD } \\
\text { cases and 123,504 non-cases) of mainly } \\
\text { European ( } 77 \% \text { ) and Asian (19\%) ancestry }\end{array}$ & www.cardiogramplusc4d.org/ \\
\hline Blood pressure & ICBP [29] & 69,395 individuals of European ancestry & $\begin{array}{l}\text { www.ncbi.nlm.nih.gov/projects/ } \\
\text { gap/cgi-bin/study.cgi?study } \\
\text { id=phs000585.v1.p1 }\end{array}$ \\
\hline Lipids & GLGC [30] & 188,577 individuals of European ancestry & $\begin{array}{l}\text { csg.sph.umich.edu/abecasis/ } \\
\text { public/lipids2013/ }\end{array}$ \\
\hline Glycaemic traits & MAGIC [31] & $\begin{array}{l}46,186 \text { non-diabetic individuals of } \\
\text { European ancestry }\end{array}$ & www.magicinvestigators.org/ \\
\hline Body mass index & GIANT [32] & $\begin{array}{l}339,224 \text { individuals of mainly European } \\
(95 \%) \text { ancestry }\end{array}$ & $\begin{array}{l}\text { portals.broadinstitute.org/collaboration/ } \\
\text { giant/index.php/GIANT_consortium }\end{array}$ \\
\hline Waist-to-hip ratio & GIANT [33] & $\begin{array}{l}224,459 \text { individuals of mainly European } \\
(94 \%) \text { ancestry }\end{array}$ & $\begin{array}{l}\text { portals.broadinstitute.org/collaboration/ } \\
\text { giant/index.php/GIANT_consortium }\end{array}$ \\
\hline Smoking & TAGC [34] & 74,053 individuals of European ancestry & $\begin{array}{l}\text { www.med.unc.edu/pgc/results-and- } \\
\text { downloads }\end{array}$ \\
\hline
\end{tabular}

CHARGE Cohorts for Heart and Aging Research in Genomic Epidemiology Consortium, GIANT Genetic Investigation of Anthropometric Traits, GLGC Global Lipids Genetics Consortium, ICBP International Consortium for Blood Pressure, MAGIC Meta-Analyses of Glucose and Insulin-related traits Consortium, TAGC Tobacco and Genetics Consortium

inversely, albeit non-statistically significantly, associated with CAD (Table 2). In conventional MR analysis, genetically predicted serum magnesium was inversely associated with $\mathrm{CAD}$, but there was evidence of heterogeneity between estimates from individual SNPs $\left(P_{\text {heterogeneity }}=0.06\right)$. The ORs of CAD per a $0.1-\mathrm{mmol} / \mathrm{L}$ (about one SD) increase in genetically predicted serum magnesium levels were 0.88 (95\% CI, 0.78-0.99; $P=0.03$ ) and 0.88 (95\% CI, 0.74-1.05; $P=0.14$ ) when standard errors were calculated using fixed-effects and random-effects models, respectively (Fig. 2). In the leave-one-out analysis, it was found that rs11144134 in the TRPM6 gene region was responsible for the heterogeneity among estimates from individual SNPs. After exclusion of this SNP, there was no heterogeneity between estimates $\left(P_{\text {heterogeneity }}=0.73\right)$, and the OR was
0.82 (95\% CI, 0.72-0.93; $P=0.002)$ in both fixed-effects and random-effects models (Fig. 2).

Results were consistent in sensitivity analyses using the weighted median (OR, 0.84; 95\% CI, 0.72-0.98; $P=0.03$ ) and heterogeneity-penalised model averaging (OR, 0.83; 95\% CI, 0.71-0.96; $P=0.02$ ) methods (Additional file 1: Table S1). The MR-Egger analysis did not provide evidence of either directional pleiotropy (intercept -0.023 ; $P=0.21)$ or a causal association $(\mathrm{OR}=1.19 ; 95 \% \mathrm{CI}$, $0.72-1.98 ; P=0.50)$, but the precision of the estimates was low (Additional file 1: Table S1). $I^{2}{ }_{\text {GX }}$ was 0.87 (relative bias of $13 \%$ towards the null), and adjusting for dilution bias using the SIMEX method did not materially change the MR-Egger estimate (Additional file 1: Table S1).

Table 2 Characteristics of the single-nucleotide polymorphisms associated with serum magnesium levels

\begin{tabular}{|c|c|c|c|c|c|c|c|c|c|c|c|c|}
\hline \multirow[b]{2}{*}{ SNP } & \multirow[b]{2}{*}{ Closest gene } & \multirow[b]{2}{*}{ Chr } & \multirow[b]{2}{*}{$E A^{b}$} & \multirow[b]{2}{*}{$\mathrm{EAF}^{\mathrm{C}}$} & \multirow[b]{2}{*}{$\%$ variance explained } & \multirow[b]{2}{*}{ F-statistic } & \multicolumn{3}{|c|}{ Association with magnesium ${ }^{a}$} & \multicolumn{3}{|c|}{ Association with $C A D^{a}$} \\
\hline & & & & & & & Beta $(\mathrm{mmol} / \mathrm{L})$ & SE & P & Beta $^{d}$ & SE & $P$ \\
\hline rs4072037 & MUC1 & 1 & $\mathrm{~T}$ & 0.54 & 0.57 & 136 & 0.010 & 0.001 & $2.0 \times 10^{-36}$ & -0.015 & 0.010 & 0.11 \\
\hline rs7965584 & ATP2B1 & 12 & A & 0.71 & 0.25 & 60 & 0.007 & 0.001 & $1.1 \times 10^{-16}$ & -0.016 & 0.011 & 0.13 \\
\hline rs3925584 & $D C D C 5$ & 11 & $\mathrm{~T}$ & 0.55 & 0.25 & 60 & 0.006 & 0.001 & $5.2 \times 10^{-16}$ & -0.016 & 0.010 & 0.09 \\
\hline rs11144134 & TRPM6 & 9 & C & 0.08 & 0.23 & 55 & 0.011 & 0.001 & $8.2 \times 10^{-15}$ & 0.039 & 0.019 & 0.04 \\
\hline rs13146355 & SHROOM3 & 4 & A & 0.44 & 0.19 & 45 & 0.005 & 0.001 & $6.3 \times 10^{-13}$ & -0.003 & 0.010 & 0.76 \\
\hline rs448378 & MDS1 & 3 & A & 0.53 & 0.13 & 30 & 0.004 & 0.001 & $1.3 \times 10^{-8}$ & -0.017 & 0.009 & 0.06 \\
\hline
\end{tabular}

CAD coronary artery disease, $C h r$ chromosome, EA effect allele, EAF effect allele frequency, $S E$ standard error, SNP single-nucleotide polymorphism

${ }^{a}$ Beta coefficients and standard errors were obtained from genome-wide association studies on serum magnesium (23,829 individuals) [22] and CAD (60,801 cases and 123,504 non-cases) [23]

${ }^{\mathrm{b}}$ Allele associated with higher serum magnesium levels

${ }^{c}$ Frequency of the magnesium-raising allele in the magnesium genome-wide association study [22]

'Log odds ratio of CAD for each additional magnesium-increasing allele

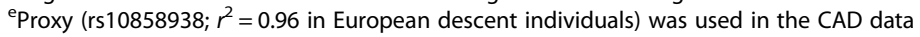




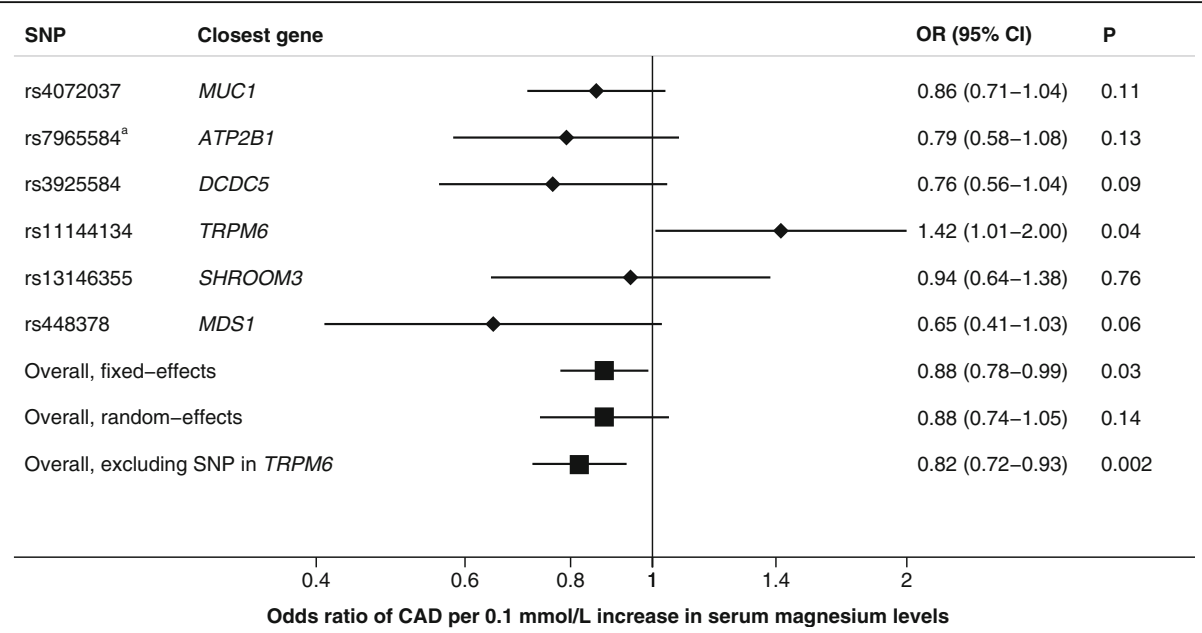

Fig. 2 Association between genetically predicted serum magnesium levels and coronary artery disease. Odds ratios are scaled to a genetically predicted 0.1 -mmol/L (about one SD) increase in serum magnesium levels. Analysis was conducted using inverse-variance weighted meta-analysis with

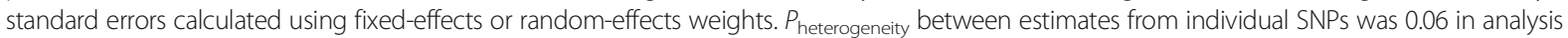
including all six SNPs and 0.74 in analysis excluding the outlying SNP in the TRPM6 gene. PProxy (rs 10858938) was used in the coronary artery disease data. CAD coronary artery disease, $\mathrm{Cl}$ confidence interval, $\mathrm{OR}$ odds ratio

In conventional MR analyses, genetic predisposition to higher serum magnesium levels was weakly associated with higher systolic blood pressure $(P=0.04)$ and triglycerides $(P=0.04)$, but was not associated with diastolic blood pressure, cholesterol, fasting glucose, fasting insulin, insulin resistance, body mass index, waist-to-hip ratio or smoking (Table 3).

\section{Discussion}

The main result of this study is that genetic variants predisposing to higher serum magnesium levels may confer a decreased risk of CAD. A genetically predicted $0.1-\mathrm{mmol} / \mathrm{L}$ (about one SD) increase in serum magnesium levels was associated with $12 \%$ lower odds of CAD in the primary analysis. This finding corroborates the results from observational prospective studies showing inverse associations of circulating magnesium levels and dietary magnesium intake with risk of coronary heart disease and cardiovascular disease [18] (Fig. 3).

There is no gold standard MR analysis method. Available methods have advantages and limitations that balance precision and adjustment for bias. In the present study, several MR approaches were applied to evaluate the robustness of the causal association between serum magnesium levels and CAD. Although we cannot entirely rule out pleiotropy, we observed a consistent inverse association between serum magnesium levels and CAD in conventional MR analysis and sensitivity analyses using the weighted median and heterogeneity-penalised model averaging methods. MR-Egger analysis, which has lower statistical power compared with the other methods, suggested no bias due to pleiotropy (i.e. when a genetic variant affects more than one phenotype) and did not detect a causal association, but the confidence interval was wide. The $I_{\mathrm{GX}}^{2}$ and $F$-statistics were high, suggesting that violation of the NOME assumption was limited and that weak instrument bias due to dilution did not materially affect the results. As in any MR study, we cannot entirely

Table 3 Associations between genetically predicted serum magnesium levels and cardiometabolic risk factors

\begin{tabular}{|c|c|c|}
\hline Outcome & Estimate $^{a}$ & $P$ value \\
\hline Continuous outcomes & Beta $(95 \% \mathrm{Cl})$ & \\
\hline Diastolic blood pressure & $0.46(-0.34$ to 1.26$) \mathrm{mm} \mathrm{Hg}$ & 0.26 \\
\hline Systolic blood pressure & 1.31 (0.05 to 2.57 ) mm Hg & 0.04 \\
\hline $\begin{array}{l}\text { Low-density lipoprotein } \\
\text { cholesterol }\end{array}$ & $0.06(-0.00$ to 0.13$) S D$ & 0.07 \\
\hline $\begin{array}{l}\text { High-density lipoprotein } \\
\text { cholesterol }\end{array}$ & $-0.03(-0.09$ to 0.03$) S D$ & 0.34 \\
\hline Triglycerides & 0.06 (0.00 to 0.12$) S D$ & 0.04 \\
\hline Fasting glucose & $0.02(-0.03$ to 0.07$) \mathrm{mmol} / \mathrm{L}$ & 0.35 \\
\hline Fasting insulin & $0.02(-0.03$ to 0.07$) \log \mathrm{pmol} / \mathrm{L}$ & 0.43 \\
\hline HOMA-IR & $0.01(-0.04$ to 0.06$)$ & 0.67 \\
\hline BMI & $-0.02(-0.07$ to 0.02$) S D$ & 0.34 \\
\hline $\begin{array}{l}\text { Waist-to-hip ratio adjusted } \\
\text { for BMl }\end{array}$ & $0.02(-0.03$ to 0.07$) \mathrm{SD}$ & 0.50 \\
\hline Cigarettes per day & $\begin{array}{l}-0.59(-1.66 \text { to } 0.49) \\
\text { cigarettes/day }\end{array}$ & 0.29 \\
\hline Binary outcomes & OR $(95 \% \mathrm{Cl})$ & \\
\hline Ever smoker & $1.00(0.98$ to 1.01$)$ & 0.62 \\
\hline Former smoker & 1.00 (0.98 to 1.02$)$ & 0.78 \\
\hline
\end{tabular}

$B M I$ body mass index, $\mathrm{Cl}$ confidence interval, HOMA-IR homeostatic model assessment of insulin resistance, $O R$ odds ratio, $S D$ standard deviation

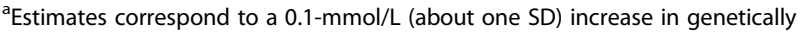
predicted serum magnesium levels 


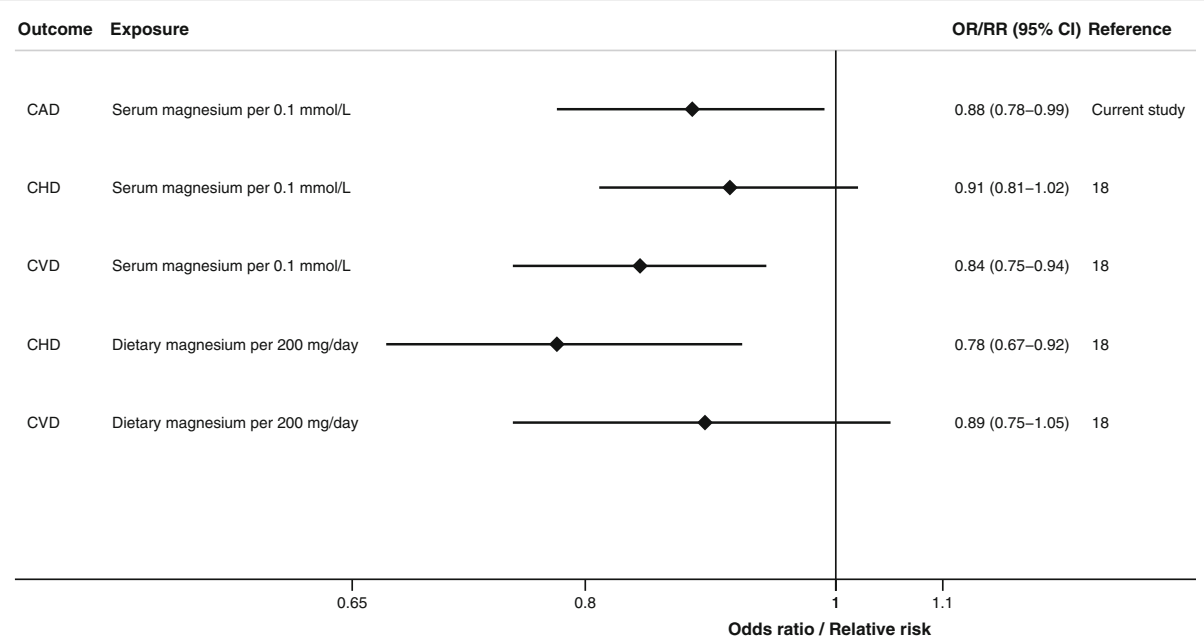

Fig. 3 Associations of serum magnesium and magnesium intake with CAD, coronary heart disease and cardiovascular disease. The summary results are from the current Mendelian randomisation study of genetically predicted serum magnesium levels in relation to CAD and a previous meta-analysis of observational prospective studies of serum magnesium levels and dietary magnesium intake in relation to coronary heart disease and cardiovascular disease. CAD coronary artery disease, CHD coronary heart disease, Cl confidence interval, CVD cardiovascular disease, OR odds ratio, $R R$ relative risk

exclude population stratification as a source of bias in this study. However, the GWAS datasets used for the present analyses largely comprised individuals of European ancestry and adjustment was made for ancestry within the contributing studies, reducing possible bias due to population stratification.

There are several plausible mechanisms whereby magnesium may affect the risk of CAD. Magnesium is involved in blood pressure regulation and in glucose and insulin metabolism [1, 2]. Meta-analyses of randomised controlled trials have shown that magnesium supplementation may modestly reduce blood pressure $[8,10-12]$, fasting glucose $[12,14]$ and insulin resistance [15]. However, we found no evidence that genetically higher magnesium levels were associated with lower blood pressure or glycaemic traits, suggesting that these risk factors are not likely mediators or confounders of the magnesium-CAD relationship. In addition, the inverse association between serum magnesium levels and CAD is unlikely explained by major lipids, as genetically higher magnesium levels were not associated with cholesterol but were weakly associated with higher triglycerides, which increase CAD risk [37].

Magnesium could potentially confer protection against CAD by enhancing endothelium-dependent vasodilation and reducing vascular resistance, oxidative stress and oxidised lipids, inflammation and thrombosis, and by anti-arrhythmic effects $[2,4,7,16,17]$. Several $[8,9,13]$ but not all $[38,39]$ randomised trials have shown that magnesium supplementation improves endothelial function and reduces arterial stiffness. The inconsistent results may be related to magnesium status among study participants, as improvement in endothelial function with magnesium supplementation was observed in trials involving patients with low serum magnesium levels [9] and patients using diuretics [8], which often cause hypomagnesaemia. Both extracellular and intracellular free magnesium can modulate vascular smooth muscle tone [2]. Extracellular magnesium is considered to be a calcium antagonist, because it inhibits many of the physiological actions of calcium [2, 40]. Magnesium decreases calcium release from and into the sarcoplasmic reticulum and protects the cells against calcium overload during myocardial ischaemia [2, 40]. Multiple lines of evidence indicate that a modestly elevated serum calcium level increases CAD risk [41-43]. In this context, mutations in TRPM6 (encoding a transient receptor potential cation channel) cause hypomagnesaemia with secondary hypocalcaemia [44, 45]. Hence, the observed positive association between the magnesium-raising allele of the genetic variant in TRPM6 and CAD might be mediated by calcium. Another magnesium-associated genetic variant is located nearby the $A T P 2 B 1$ gene, which encodes plasma-membrane calcium ATPase responsible for removal of calcium ions from cells [22].

A limitation of this study is that the specific biological functions of most of the genetic variants associated with serum magnesium levels are unknown (Additional file 1: Table S2). However, the magnesium-associated SNPs have shown association with hypomagnesaemia and with phenotypes related to serum magnesium levels, such as fasting glucose (SNP in MUC1), bone mineral density (SNPs in MUC1 and TRPM6) and kidney function (SNPs in SHROOM3 and DCDC5) [22]. Kidney function has been associated with cardiovascular disease risk in 
observational studies [46], but there was little support for a causal association between kidney function and coronary heart disease in a recent MR analysis [47], suggesting that the observed association between magnesium levels and CAD in the present study is unlikely mediated by kidney function. Further research is needed to better understand the role of the genetic variants and their link to circulating and intracellular magnesium levels.

\section{Conclusions}

This study based on genetics provides evidence that serum magnesium levels are inversely associated with risk of CAD. Randomised controlled trials elucidating whether magnesium supplementation reduces the risk of CAD are warranted. As magnesium supplementation is expected to be most beneficial in individuals with an inadequate magnesium status, such a trial may preferably involve a setting with persons at higher risk of hypomagnesaemia.

\section{Additional file}

Additional file 1: Table S1. Association of genetically predicted $0.1-\mathrm{mmol} / \mathrm{L}$ increase in serum magnesium with coronary artery disease in inverse-variance weighted and sensitivity analyses. Table S2. Genes located in or near the loci for serum magnesium and their biological roles. (DOCX $56 \mathrm{~kb}$ )

\section{Abbreviations}

CAD: Coronary artery disease; Cl: Confidence interval; GWAS: Genome-wide association study; NOME: NO Measurement Error; OR: Odds ratio; SD: Standard deviation; SIMEX: Simulation extrapolation; SNP: Singlenucleotide polymorphism

\section{Acknowledgements}

Data on genetic associations with CAD have been contributed by CARDIoGRAMplusC4D investigators and have been downloaded from www.cardiogramplusc4d.org/. Data on genetic associations with glycaemic traits have been contributed by the Meta-Analyses of Glucose and Insulin-related traits Consortium (MAGIC) investigators and have been downloaded from www.magicinvestigators.org. The authors also wish to thank the Tobacco and Genetics Consortium (TAGC), the International Consortium for Blood Pressure (ICBP) Genome-Wide Association Studies (dbGaP accession phs000585.v1.p1), the Global Lipids Genetics Consortium (GLGC) and the Genetic Investigation of Anthropometric Traits (GIANT) Consortium for access to their data.

\section{Availability of data and materials}

All data generated or analysed during this study are included in this published article and its additional files.

\section{Authors' contributions}

SCL had full access to all of the data in the study and takes responsibility for the integrity of the data and the accuracy of the data analysis. SCL, SB and KM conceived and designed the study. $\mathrm{SCL}$ acquired the data and performed the statistical analysis. SCL, SB and KM interpreted the data. SCL drafted the manuscript. SCL, SB and KM critically revised the manuscript for important intellectual content. All authors read and approved the final manuscript.

\section{Ethics approval and consent to participate}

Ethical approval was not sought, because this study involved analysis of publicly available summary-level data from GWASs, and no individual-level data were used.

\section{Competing interests}

The authors declare that they have no competing interests.

\section{Publisher's Note}

Springer Nature remains neutral with regard to jurisdictional claims in published maps and institutional affiliations.

\section{Author details}

'Unit of Nutritional Epidemiology, Institute of Environmental Medicine, Karolinska Institutet, 17177 Stockholm, Sweden. ${ }^{2}$ MRC Biostatistics Unit, University of Cambridge, Cambridge, UK. ${ }^{3}$ Department of Public Health and Primary Care, University of Cambridge, Cambridge, UK. ${ }^{4}$ Department of Surgical Sciences, Uppsala University, Uppsala, Sweden.

Received: 18 January 2018 Accepted: 26 April 2018

Published online: 17 May 2018

\section{References}

1. Volpe SL. Magnesium, the metabolic syndrome, insulin resistance, and type 2 diabetes mellitus. Crit Rev Food Sci Nutr. 2008;48:293-300.

2. Kolte D, Vijayaraghavan K, Khera S, Sica DA, Frishman WH. Role of magnesium in cardiovascular diseases. Cardiol Rev. 2014;22:182-92.

3. Maier JA. Endothelial cells and magnesium: implications in atherosclerosis. Clin Sci (Lond). 2012;122:397-407.

4. Zheltova AA, Kharitonova MV, lezhitsa IN, Spasov AA. Magnesium deficiency and oxidative stress: an update. Biomedicine (Taipei). 2016;6:20.

5. Chaudhary DP, Boparai RK, Bansal DD. Implications of oxidative stress in high sucrose low magnesium diet fed rats. Eur J Nutr. 2007;46:383-90.

6. Adrian $M$, Chanut $E$, Laurant $P$, Gaume $V$, Berthelot A. A long-term moderate magnesium-deficient diet aggravates cardiovascular risks associated with aging and increases mortality in rats. J Hypertens. 2008;26:44-52.

7. Morais JB, Severo JS, Santos LR, de Sousa Melo SR, de Oliveira SR, de Oliveira $A R$, et al. Role of magnesium in oxidative stress in individuals with obesity. Biol Trace Elem Res. 2017;176:20-6.

8. Cunha AR, D'El-Rei J, Medeiros F, Umbelino B, Oigman W, Touyz RM, et al. Oral magnesium supplementation improves endothelial function and attenuates subclinical atherosclerosis in thiazide-treated hypertensive women. J Hypertens. 2017;35:89-97.

9. Shechter M, Sharir M, Labrador MJ, Forrester J, Silver B, Bairey Merz CN. Oral magnesium therapy improves endothelial function in patients with coronary artery disease. Circulation. 2000;102:2353-8.

10. Zhang X, Li Y, Del Gobbo LC, Rosanoff A, Wang J, Zhang W, et al. Effects of magnesium supplementation on blood pressure: a meta-analysis of randomized double-blind placebo-controlled trials. Hypertension. 2016;68:324-33.

11. Dibaba DT, Xun P, Song Y, Rosanoff A, Shechter M, He K. The effect of magnesium supplementation on blood pressure in individuals with insulin resistance, prediabetes, or noncommunicable chronic diseases: a meta-analysis of randomized controlled trials. Am J Clin Nutr. 2017;106:921-9.

12. Verma H, Garg R. Effect of magnesium supplementation on type 2 diabetes associated cardiovascular risk factors: a systematic review and meta-analysis. J Hum Nutr Diet. 2017;30:621-33.

13. Joris PJ, Plat J, Bakker SJ, Mensink RP. Long-term magnesium supplementation improves arterial stiffness in overweight and obese adults: results of a randomized, double-blind, placebo-controlled intervention trial. Am J Clin Nutr. 2016:103:1260-6.

14. Song Y, He K, Levitan EB, Manson JE, Liu S. Effects of oral magnesium supplementation on glycaemic control in Type 2 diabetes: a meta-analysis of randomized double-blind controlled trials. Diabet Med. 2006;23:1050-6.

15. Simental-Mendia LE, Sahebkar A, Rodriquez-Moran M, Guerrero-Romero F. A systematic review and meta-analysis of randomized controlled trials on the effects of magnesium supplementation on insulin sensitivity and glucose control. Pharmacol Res. 2016;111:272-82.

16. Lee HY, Ghimire S, Kim EY. Magnesium supplementation reduces postoperative arrhythmias after cardiopulmonary bypass in pediatrics: a metaanalysis of randomized controlled trials. Pediatr Cardiol. 2013:34:1396-403.

17. Shiga T, Wajima Z, Inoue T, Ogawa R. Magnesium prophylaxis for arrhythmias after cardiac surgery: a meta-analysis of randomized controlled trials. Am J Med. 2004;117:325-33.

18. Del Gobbo LC, Imamura F, Wu JH, de Oliveira Otto MC, Chiuve SE, Mozaffarian D. Circulating and dietary magnesium and risk of cardiovascular disease: a systematic review and meta-analysis of prospective studies. Am J Clin Nutr. 2013;98:160-73. 
19. Fang X, Liang C, Li M, Montgomery S, Fall K, Aaseth J, et al. Dose-response relationship between dietary magnesium intake and cardiovascular mortality: a systematic review and dose-based meta-regression analysis of prospective studies. J Trace Elem Med Biol. 2016:38:64-73.

20. Moshfegh AJ, Goldmand JD, Ahuja JKC, LaComb RP. What we eat in America, NHANES 2005-2006: usual nutrient intakes from food and water compared to 1997 dietary references intakes for vitamin D, calcium, phosphorus, and magnesium. US: Department of Agriculture, Agricultural Research Service; 2009.

21. Burgess S, Thompson SG: Mendelian randomization: methods for using genetic variants in causal estimation. London: Chapman \& Hall; 2015.

22. Meyer TE, Verwoert GC, Hwang SJ, Glazer NL, Smith AV, van Rooij FJ, et al. Genome-wide association studies of serum magnesium, potassium, and sodium concentrations identify six loci influencing serum magnesium levels. PLoS Genet. 2010;6:e1001045.

23. Nikpay M, Goel A, Won HH, Hall LM, Willenborg C, Kanoni S, et al. A comprehensive 1,000 Genomes-based genome-wide association meta-analysis of coronary artery disease. Nat Genet. 2015;47:1121-30.

24. Burgess S, Bowden J, Fall T, Ingelsson E, Thompson SG. Sensitivity analyses for robust causal inference from Mendelian randomization analyses with multiple genetic variants. Epidemiology. 2017;28:30-42.

25. Burgess S, Zuber V, Gkatzionis A, Rees JMB, Foley C. Improving on a modal-based estimation method: model averaging for consistent and efficient estimation in Mendelian randomization when a plurality of candidate instruments are valid. BioRxiv https://doi.org/10.1101/175372. 2017.

26. Burgess S, Thompson SG. Interpreting findings from Mendelian randomization using the MR-Egger method. Eur J Epidemiol. 2017;32:377-89.

27. Bowden J, Del Greco MF, Minelli C, Davey Smith G, Sheehan NA, Thompson JR. Assessing the suitability of summary data for two-sample Mendelian randomization analyses using MR-Egger regression: the role of the 12 statistic Int J Epidemiol. 2016;45:1961-74

28. Burgess S, Thompson SG. Avoiding bias from weak instruments in Mendelian randomization studies. Int J Epidemiol. 2011;40:755-64.

29. Ehret GB, Munroe PB, Rice KM, Bochud M, Johnson AD, Chasman DI, et al. Genetic variants in novel pathways influence blood pressure and cardiovascular disease risk. Nature. 2011:478:103-9.

30. Willer CJ, Schmidt EM, Sengupta S, Peloso GM, Gustafsson S, Kanoni S, et al. Discovery and refinement of loci associated with lipid levels. Nat Genet. 2013;45:1274-83.

31. Dupuis J, Langenberg C, Prokopenko I, Saxena R, Soranzo N, Jackson AU, et al. New genetic loci implicated in fasting glucose homeostasis and their impact on type 2 diabetes risk. Nat Genet. 2010;42:105-16.

32. Locke AE, Kahali B, Berndt SI, Justice AE, Pers TH, Day FR, et al. Genetic studies of body mass index yield new insights for obesity biology. Nature. 2015;518:197-206.

33. Shungin D, Winkler TW, Croteau-Chonka DC, Ferreira T, Locke AE, Magi R, et al. New genetic loci link adipose and insulin biology to body fat distribution. Nature. 2015;518:187-96.

34. Tobacco and Genetics Consortium. Genome-wide meta-analyses identify multiple loci associated with smoking behavior. Nat Genet. 2010;42:441-7.

35. Spiller W, Davies NM, Palmer TM. Software application profile: mrrobust - a tool for performing two-sample summary Mendelian randomization analyses. BioRxiv https://doi.org/10.1101/142125. 2017.

36. Yavorska OO, Burgess S. MendelianRandomization: an R package for performing Mendelian randomization analyses using summarized data. Int J Epidemiol. 2017; https://doi.org/10.1093/ije/dyx034. [Epub ahead of print].

37. Holmes MV, Asselbergs FW, Palmer TM, Drenos F, Lanktree MB, Nelson CP, et al. Mendelian randomization of blood lipids for coronary heart disease. Eur Heart J. 2015;36:539-50.

38. Joris PJ, Plat J, Bakker SJ, Mensink RP. Effects of long-term magnesium supplementation on endothelial function and cardiometabolic risk markers: a randomized controlled trial in overweight/obese adults. Sci Rep. 2017;7:106

39. Cosaro E, Bonafini S, Montagnana M, Danese E, Trettene MS, Minuz P, et al. Effects of magnesium supplements on blood pressure, endothelial function and metabolic parameters in healthy young men with a family history of metabolic syndrome. Nutr Metab Cardiovasc Dis. 2014;24:1213-20.

40. Iseri LT, French JH. Magnesium: nature's physiologic calcium blocker. Am Heart J. 1984;108:188-93.

41. Larsson SC, Burgess S, Michaelsson K. Association of genetic variants related to serum calcium levels with coronary artery disease and myocardial infarction. JAMA. 2017;318:371-80.
42. Bolland MJ, Grey A, Avenell A, Gamble GD, Reid IR. Calcium supplements with or without vitamin D and risk of cardiovascular events: reanalysis of the Women's Health Initiative limited access dataset and meta-analysis. BMJ. 2011:342:d2040.

43. Reid IR, Gamble GD, Bolland MJ. Circulating calcium concentrations, vascular disease and mortality: a systematic review. J Intern Med. 2016;279:524-40.

44. Schlingmann KP, Weber S, Peters M, Niemann Nejsum L, Vitzthum H, Klingel K, et al. Hypomagnesemia with secondary hypocalcemia is caused by mutations in TRPM6, a new member of the TRPM gene family. Nat Genet. 2002;31:166-70.

45. Lainez S, Schlingmann KP, van der Wijst J, Dworniczak B, van Zeeland F, Konrad M, et al. New TRPM6 missense mutations linked to hypomagnesemia with secondary hypocalcemia. Eur J Hum Genet. 2014;22:497-504.

46. Pattaro C, Teumer A, Gorski M, Chu AY, Li M, Mijatovic V, et al. Genetic associations at 53 loci highlight cell types and biological pathways relevant for kidney function. Nat Commun. 2016;7:10023.

47. Charoen P, Nitsch D, Engmann J, Shah T, White J, Zabaneh D, et al. Mendelian randomisation study of the influence of eGFR on coronary heart disease. Sci Rep. 2016;6:28514.

\section{Ready to submit your research? Choose BMC and benefit from:}

- fast, convenient online submission

- thorough peer review by experienced researchers in your field

- rapid publication on acceptance

- support for research data, including large and complex data types

- gold Open Access which fosters wider collaboration and increased citations

- maximum visibility for your research: over $100 \mathrm{M}$ website views per year

At BMC, research is always in progress.

Learn more biomedcentral.com/submissions 